\title{
ESTUDOS FÍSICO-QUÍMICOS E MICROBIOLÓGICOS DA EFICIÊNCIA DO TRATAMENTO DE EFLUENTE PROVENIENTE DE ABATEDOURO AVÍCOLA
}

José Eduardo Gonçalves*

Rebecca Manesco Paixão**

Luiz Henrique Biscaia Ribeiro da Silva" ${ }^{* * *}$

RESUMO: O processo de industrialização do frango demanda uma elevada quantidade de água potável em decorrência dos vários procedimentos utilizados, assim este efluente contém uma elevada carga de matéria orgânica e sólidos, necessitando de tratamentos adequados para poder, por fim, ser disposto no corpo hídrico receptor. Este efluente deve atender aos parâmetros exigidos pelo Conselho Nacional do Meio Ambiente (CONAMA) para não causar prejuízos irreparáveis ao meio ambiente. Este estudo teve o objetivo de avaliar parâmetros físico-químicos, como $\mathrm{pH}, \mathrm{DBO}_{5}, \mathrm{DQO}$, nitrogênio e fósforo, e microbiológicos para a presença de coliformes totais e termotolerantes, de efluentes provenientes de abatedouro avícola. Foram coletadas duas amostras por mês no período da tarde durante 06 meses para o sistema de entrada (primeira lagoa de tratamento - lagoa anaeróbica) e para o sistema de saída (última lagoa - lagoa de polimento). Os resultados obtidos mostraram que não houve uma remoção adequada para a carga microbiana quando comparados os valores de entrada e saída do sistema de tratamento. E nas análises físico-químicas, mesmo apresentando uma taxa de remoção superior a 90\%, não atingiu os valores máximos permitidos pela legislação ambiental para o lançamento do efluente no corpo hídrico receptor, demonstrando que o abatedouro avícola em questão necessita de uma estruturação de seu sistema de lagoas de tratamento para que não degrade o corpo hídrico receptor.

PALAVRAS-CHAVE: Efluente Avícola; Parâmetros Físico-químico e Microbiológico; Sistema de Lagoa de Tratamento.

\footnotetext{
Doutor em Química pela Universidade Estadual de Campinas (UNICAMP); Docente Permanente dos Programas de Mestrado em Tecnologias Limpas e em Promoção da Saúde da UniCesumar - Centro Universitário Cesumar, Maringá, Brasil; E-mail: jose.goncalves@unicesumar.edu.br

** Engenheira Ambiental e Sanitárista - UniCesumar - Centro Universitário Cesumar; Mestranda no Programa de Pós-graduação em Engenharia Química na Universidade Estadual de Maringá (UEM), Brasil.

*** Engenheiro Ambiental e Sanitárista - UniCesumar - Centro Universitário Cesumar; Mestrando no Programa de Pós-graduação em Engenharia Química na Universidade Estadual de Maringá (UEM), Brasil.
} 


\section{PHYSICAL, CHEMICAL AND MICROBIOLOGICAL STUDIES ON THE EFFICIENCY OF TREATMENTS OF EFFLUENT FROM FOWL ABATTOIR}

ABSTRACT: Fowl industrialization requires a high quantity of drinkable water due to the several procedures employed. The effluent contains a high load of organic matter and solids requiring adequate treatments to dispose of in the receiving water body. The effluent should comply with parameters required by the Brazilian Council for the Environment (CONAMA) so that irreparable damage to the environment may be avoided. Current analysis evaluated the physical and chemical parameters, such as $\mathrm{pH}, \mathrm{BOD}_{5}, \mathrm{COD}$, nitrogen and phosphorus, and microbiological parameters for total and thermotolerant coliforms of effluents from the fowl abattoir. Two samples were collected per month, in the afternoon, during six months for entrance (first treatment lake - anaerobic lake) and exit (last lake - polishing lake) system. Results showed that there was no adequate removal for microbial load when entrance and exit rates in the system of treatment were compared. Physical and chemical analyses, albeit with a $90 \%$ removal rate, did not reach maximum rates permitted by environmental legislation for effluents to be disposed of into the receiving water body. The fowl abattoir requires a more adequate structuring of its treatment lake systems so that the receiving water body would not be degraded.

KEY WORDS: Fowl Abattoir Effluents; Physical, Chemical and Microbiological Parameters; Treatment Lake System.

\section{INTRODUÇÃO}

O aumento populacional aliado a uma modernização dos processos produtivos fez com que a indústria avícola se adaptasse à nova realidade do mercado consumidor. Contudo, houve um aumento crescente na geração de efluentes e resíduos pelas indústrias avícolas, tornando-se necessárias novas alternativas de tratamento e disposição destes, de forma que os parâmetros estipulados pela legislação ambiental fossem cumpridos (MENEGAZ et al., 2011; MOLINO et al., 2013; KHALID et al., 2011; ALVAREZ; LIDÉN, 2008).

O processo de industrialização do frango pelas indústrias de abate apresenta 
uma elevada demanda de água potável em decorrência dos vários procedimentos utilizados, entre eles a higienização (ave, equipamentos e piso), a escaldagem e o resfriamento. Durante esses processos, ocorre a geração de alta carga de matéria orgânica e sólidos, tornando-o um efluente poluidor, e o lançamento deste in natura acarretará sérios prejuízos ao meio ambiente (MENEGAZ et al., 2011; ZENATTI et al., 2009; CHEN; CREAMER, 2008; SALMINEN; RINATA, 2002).

Um efluente com elevado teor de matéria orgânica, como o gerado pelo setor avícola (BARROS et al., 2007; BARROS et al., 2012; OLIVEIRA et al., 2011), necessita de tratamento preliminar, a fim de remover sólidos grosseiros, tratamento primário para remoção de sólidos sedimentáveis e parte da matéria orgânica, e tratamento secundário, ou biológico, objetivando a remoção de matéria orgânica, alguns nutrientes como o fósforo e o nitrogênio, e demanda bioquímica de oxigênio (DBO) em suspensão e solúvel, para poder, por fim, ser disposto no corpo hídrico receptor (VON SPERLING, 2005).

No Brasil, o Conselho Nacional do Meio Ambiente (CONAMA), instituído pela Lei $\mathrm{n}^{\circ}$ 6.938, de 1981, mudou os rumos da política ambiental do país e, atualmente, a Resolução CONAMA n ${ }^{\circ} 357$, de 2005, alterada e complementada pela Resolução CONAMA no 430, de 2011, tornou-se um importante instrumento, que dispõe sobre a classificação dos corpos de água e diretrizes ambientais para o seu enquadramento, assim como estabelece as condições e padrões de lançamento de efluentes, visando uma melhor qualidade ambiental no país.

O presente estudo tem por objetivo avaliar a eficiência de remoção da carga orgânica e dos patógenos no sistema de tratamento de efluentes de um abatedouro avícola, por meio de análises físico-químicas (determinação do $\mathrm{pH}$, demanda química de oxigênio (DQO), demanda bioquímica de oxigênio (DBO), nitrogênio e fósforo) e microbiológica (determinação de coliformes totais e coliformes termotolerantes), da entrada e saída dos sistemas de lagoa de tratamento, a fim de comparar os resultados com a legislação vigente, para verificar se o tratamento proposto para os efluentes está sendo eficiente e, também, se o lançamento dos efluentes nos corpos hídricos receptores atendem aos parâmetros legais exigidos pela Resolução CONAMA n 357 , 
de 2005, alterada e complementada pela Resolução CONAMA no 430, de 2011, bem como pela licença de operação da empresa, concedida pelo Instituto Ambiental do Paraná (IAP), minimizando os possíveis impactos ambientais.

\section{MATERIAIS E MÉTODOS}

Foi investigado um abatedouro avícola localizado no Norte do Estado do Paraná, de médio a grande porte, o qual abate cerca de 150.000 aves ao dia, podendo haver oscilações para mais ou para menos. No local, utilizam-se 25 litros de água para cada ave abatida.

O Quadro 1 apresenta os locais onde este volume de água é utilizado nas diferentes etapas do processamento avícola.

Quadro 1. Tipos de dejetos e sub-produtos produzidos nas diferentes etapas do processamento avícola

\begin{tabular}{|l|l|}
\hline \multicolumn{1}{|c|}{ Etapa do processamento } & \multicolumn{1}{c|}{ Tipo de dejeto ou sub-produto } \\
\hline Recepção & Fezes, penas, água de limpeza \\
\hline Sacrifício & Sangue, água de limpeza \\
\hline Escalda/Depenamento & Penas, sangue/gordura, água de limpeza \\
\hline Evisceração & $\begin{array}{l}\text { Vísceras, sangue, gordura, pequenos pedaços de carne, } \\
\text { água de limpeza }\end{array}$ \\
\hline Resfriamento & $\begin{array}{l}\text { Sangue, gordura, pequenos pedaços de carne, água de } \\
\text { limpeza }\end{array}$ \\
\hline Classificação e empacotamento & Água de limpeza \\
\hline Limpeza da planta & Água de limpeza \\
\hline
\end{tabular}

Os subprodutos como cabeças, pés, sangue, vísceras não comestíveis, intestinos livres de conteúdo fecal e pedaços de carcaças ou mesmo carcaças inteiras impróprias para o consumo humano, no abate de aves são obtidos pela autoclavagem seguida de secagem e moagem. São utilizadas canaletas para separar o sangue retirado da sangria, onde devido ao seu alto valor comercial, este resíduo é reaproveitado como farinha na nutrição animal. As vísceras também são separadas 
através de canaletas e juntamente com as penas que são separadas por peneiras e transformadas em farinhas também utilizadas para os mesmos fins. A água residuária utilizada para levar e transformar os resíduos em subprodutos, ainda passa pelo flotador (tratamento físico) para a retirada de gordura. A gordura retida é encaminhada para a fabricação de óleo, que assim como os demais resíduos são utilizados para a nutrição animal. Após a passagem da água pelo flotador, esta é encaminhada para o sistema de tratamento de efluentes.

O sistema de tratamento de efluentes da indústria em questão é composto por sete lagoas, sendo duas lagoas anaeróbicas, três facultativas, uma aerada e uma de polimento.

Os pontos de amostragem foram a entrada e a saída do sistema de lagoas de tratamento, sendo que na entrada foram retiradas amostras da primeira lagoa ou lagoa anaeróbica, e da saída foram retiradas amostras da última lagoa ou lagoa de polimento, a qual o destino final dos efluentes será o corpo hídrico receptor, enquadrado como água doce classe II, de acordo com a Resolução CONAMA n ${ }^{\circ}$ 357 , de 2005.

Os procedimentos de coleta ocorreram em dias normais de expediente, durante 06 (seis) meses, sempre no período da tarde (primeiras horas da tarde). Todos os meses foram coletados duas amostras na entrada e duas amostras na saída do sistema de tratamento de lagoas, onde uma amostra de cada lagoa (entrada e saída) foi destinada para análise microbiológica e as outras duas amostras restantes destinadas para análises físico-químicas.

Para as análises microbiológicas foi investigada a presença de coliformes totais e coliformes termotolerantes. O procedimento adotado para análise destes protocolos foi o método do Número Mais Provável (NMP), que é a metodologia da Americam Public Health (APHA, 2012).

Para os mesmos pontos de entrada e saída também foram realizadas análises físico-químicas para determinação de $\mathrm{pH}, \mathrm{DBO}_{5}$, DQO, nitrogênio e fósforo (MENDHAM et al., 2002), verificando o perfil das lagoas e sua eficiência.

Em todas as análises, as amostras foram preparadas no laboratório de Análise Química e Biotecnológica do Centro Universitário Cesumar - UniCesumar e analisadas por metodologias já estabelecidas para análise de efluentes. 


\section{RESULTADOS E DISCUSSÃO}

\subsection{ANÁLISE MICROBIOLÓGICA DOS EFLUENTES}

\subsubsection{Determinação de coliformes totais e coliformes fecais}

Para as análises microbiológicas de coliformes totais e coliformes termotolerantes, a redução destes apresentou índices variáveis durante os meses investigados. E ainda, os resultados encontrados de ambos foram semelhantes para a entrada e saída das lagoas de tratamento (Tabela 1).

Tabela 1. Análise de coliformes totais e fecais do sistema de lagoas de tratamento

\begin{tabular}{c|cc|cc}
\hline \multirow{2}{*}{ mês } & \multicolumn{2}{|c|}{ Coliformes totais NMP/mL } & \multicolumn{2}{c}{ Coliformes fecais NMP/mL } \\
\cline { 2 - 5 } & Entrada & Saída & Entrada & Saída \\
\hline 1 & 2420 & 480 & 2400 & 460 \\
2 & 2420 & 1150 & 2400 & 1100 \\
3 & 2420 & 2420 & 2400 & 2400 \\
4 & 2420 & 2420 & 2400 & 2400 \\
5 & 2420 & 1150 & 2400 & 1100 \\
6 & 2420 & 1150 & 2400 & 1100 \\
\hline
\end{tabular}

Para $\geq 2420$, tem-se intervalo de confiança: mínimo $>150$ e máximo $>4800$ e para $\geq 480$, temse intervalo de confiança: mínimo 71 e máximo 2400.

Através da comparação dos resultados (Tabela 1) observou-se que para as análises do $3^{\circ}$ e $4^{\circ}$ mês não houve redução da carga microbiana entre a entrada e a saída da lagoa de tratamento, e para os outros meses de análise, a redução tanto para coliformes totais, quanto para os coliformes fecais, não foi adequada, uma vez que a saída do sistema apresentou grande concentração de coliformes não atendendo ao limite de 1000 coliformes termotolerantes por 100 mililitros, estabelecido pela 
Resolução CONAMA no 357, de 2005.

$\mathrm{Na}$ indústria avícola, sabe-se que os resíduos do processamento das aves (penas, esterco, sangue, gorduras e vísceras) por conter materiais sob a forma de carboidratos, proteínas e gorduras, aceleram o crescimento dos microrganismos presentes. Além desses resíduos do processamento, também é descartada a água residuária utilizada na escalda, depenamento, evisceração, resfriamento, classificação, empacotamento e limpeza da planta. Esta água residuária que subdivide-se em linha verde (que compreende os efluentes provenientes da recepção, sangria e escalda); linha vermelha (reúnem-se os efluentes provenientes das outras fases do processo, com exceção dos efluentes sanitários); e efluente sanitário (proveniente dos banheiros, vestiários e áreas administrativas), que após alguns processos, também tem como destino as lagoas de tratamento, contribuindo com o crescimento microbiano, principalmente gerando ambiente propício aos coliformes, atingindo-se assim, picos relativamente altos na análise do Número Mais Provável (NMP) tanto de coliformes totais, quanto de coliformes termotolerantes por mililitros nas amostras analisadas de efluente, tanto para a entrada, quanto para a saída do sistema de lagoas de tratamento.

Estes resultados nos mostram que o sistema de lagoas de tratamento utilizado pelo abatedouro avícola em questão não está atendendo à legislação ambiental (Resolução CONAMA no 357 , de 2005) e a presença de patógenos, como os coliformes totais e fecais, em quantidade superior ao recomendado pode acarretar em doenças de veiculação hídrica (VON SPERLING, 2005).

Através das provas bioquímicas foi evidenciada uma variedade de Enterobacteriáceas presentes nas lagoas de tratamento (anaeróbica e polimento), como demostrado na Tabela 2.

Observando os dados descritos na Tabela 2 para as provas bioquímicas podemos destacar a prevalência da bactéria Escherichia coli encontrada em todas as amostras analisadas (lagoa anaeróbica e de polimento) e representando a maior porcentagem. Na lagoa de tratamento anaeróbica encontramos também cinco amostras com a presença da Proteus miriabilis enquanto que para a lagoa de polimento em três amostras observou-se a presença da Proteus vulgaris. 
Tabela 2. Resultados em porcentagem das bactérias encontradas nas lagoas de entrada (anaeróbica) e de saída (polimento)

\begin{tabular}{l|c|c|c|c|c|c|c|c|c|c|c|c}
\hline & \multicolumn{2}{|c|}{$1^{0}$ mês } & \multicolumn{2}{|c|}{$2^{0}$ mês } & \multicolumn{2}{|c|}{$3^{0}$ mês } & \multicolumn{2}{|c|}{$4^{0}$ mês } & \multicolumn{2}{|c|}{$5^{0}$ mês } & \multicolumn{2}{|c}{$6^{0}$ mês } \\
\hline Bactérias & LA & LP & LA & LP & LA & LP & LA & LP & LA & LP & LA & LP \\
\hline $\begin{array}{l}\text { Edwardsiella } \\
\text { tarda }\end{array}$ & - & - & - & - & - & - & 20 & - & 10 & - & - & - \\
\hline $\begin{array}{l}\text { Enterobacter } \\
\text { cloaceae }\end{array}$ & - & - & 25 & - & - & - & - & - & 20 & - & - & - \\
\hline $\begin{array}{l}\text { Escherichia } \\
\text { coli }\end{array}$ & 50 & 66 & 50 & 40 & 33 & 100 & 40 & 50 & 50 & 67 & 50 & 50 \\
\hline $\begin{array}{l}\text { Háfnia alvei } \\
\text { Klebsciella } \\
\text { pneumoniae }\end{array}$ & -17 & - & - & - & - & - & - & - & - & - & 25 & - \\
\hline $\begin{array}{l}\text { Kluivera } \\
\text { ascorbata }\end{array}$ & - & - & - & - & 17 & - & - & - & - & - & - & - \\
\hline $\begin{array}{l}\text { Morganella } \\
\text { morganii }\end{array}$ & - & - & - & - & 17 & - & - & - & - & - & - & - \\
\hline $\begin{array}{l}\text { Providência } \\
\text { alcalifaciens }\end{array}$ & - & - & - & 20 & - & - & - & - & - & - & - & 10 \\
\hline $\begin{array}{l}\text { Proteus } \\
\text { miriabilis }\end{array}$ & 16 & - & 25 & - & - & - & 40 & - & 20 & - & 25 & - \\
\hline $\begin{array}{l}\text { Proteus } \\
\text { pennari }\end{array}$ & - & - & - & - & - & - & - & $50 \%$ & - & - & - & 20 \\
\hline $\begin{array}{l}\text { Proteus } \\
\text { vulgaris }\end{array}$ & 17 & 34 & - & 20 & 33 & - & - & - & - & 34 & - & - \\
\hline IA & - & - & - & - & - & - & - & - & 20 \\
\hline
\end{tabular}

LA = lagoa anaeróbica (entrada) e LP = lagoa de polimento (saída).

A confirmação destas Enterobacteriáceas através das provas bioquímicas justifica-se pela presença de resíduos provenientes do processamento, da água residuária (mesmo apresentando um sistema de cloração na planta) e também por haver uma grande concentração de efluente sanitário que tem por destino as lagoas de tratamento, após passar por um processo de peneiramento. Estes 
valores percentuais encontrados confirmam os resultados determinados na análise de coliformes totais e termotolerantes, de acordo com a Tabela do Número Mais Provável (SILVA, 2005).

É necessário lembrar também que muitas bactérias encontradas em uma amostra, e não encontradas nas análises subsequentes, podem estar presentes na entrada ou saída do sistema de tratamento, já que fora realizada amostragem simples, podendo não terem sido identificadas no momento da amostragem.

Os valores encontrados através da realização das provas bioquímicas evidenciaramaineficiência do sistema em reduzir acargabacteriana, principalmente ao verificar a bactéria Escherichia coli. Dentre as bactérias de habitat reconhecidamente fecal (grupo coliformes termotolerantes), a Escherichia coli é a mais conhecida e a mais facilmente diferenciada dos membros não fecais, e sua presença no efluente lançado no corpo do rio pode acometer a saúde das pessoas (BARROS et al., 2012).

\subsection{ANÁLISE FÍSICO-QUÍMICA DOS EFLUENTES}

A Tabela 3 apresenta os valores de pH obtidos na entrada e saída do sistema de lagoa de tratamento de efluentes do abatedouro avícola. Os valores obtidos na saída do sistema de lagoas não comprometem a faixa de $\mathrm{pH}$ do corpo hídrico receptor permitida pela Resolução CONAMA no 430, de 2011, a qual estabelece valores de emissão para efluentes com pH na faixa de 5 a 9 .

Tabela 3. Medidas de pH obtido no sistema de lagoas de tratamento

\begin{tabular}{c|cc}
\hline mês & $\begin{array}{c}\text { Lagoa anaeróbica - entrada } \\
\mathrm{pH}\end{array}$ & $\begin{array}{c}\text { Lagoa de polimento - saída } \\
\mathrm{pH}\end{array}$ \\
\hline 1 & 7,1 & 8,0 \\
2 & 6,5 & 7,7 \\
3 & 7,2 & 8,4 \\
4 & 6,8 & 7,8 \\
5 & 7,1 & 8,0 \\
6 & 7,3 & 8,5 \\
\hline
\end{tabular}


Os valores de $\mathrm{pH}$ encontrados não apresentaram variações bruscas durantes os meses de análise, e observou-se também que o $\mathrm{pH}$ na saída do sistema de tratamento é um pouco maior quando comparado ao $\mathrm{pH}$ da entrada da lagoa de tratamento, fato este característico do efluente industrial que passa por processo de tratamento.

Comparando os valores demonstrados na Tabela 3 com os relatados na literatura (BARROS et al., 2012; BARROS et al., 2007; MOLINO et al., 2013; KHALID et al., 2011; SALMINEN; RINTALA, 2002) encontramos similaridade com os valores de $\mathrm{pH}$, onde os mesmos devem ter $\mathrm{pH}$ próximos do neutro para uma melhor atividade das lagoas, sendo assim possível alcançar atividade microbiológica eficiente para a quebra da matéria orgânica presente nos efluentes, com subsequente formação de material celular.

\subsubsection{Determinação da Demanda Bioquímica de Oxigênio - $\mathrm{DBO}_{5}$}

No momento da coleta, ambas as amostras (da entrada e da saída dos sistemas de lagoas) foram retiradas por amostragem pontual ou simples. A amostragem simples não permite valores reais das análises realizadas na primeira lagoa (lagoa anaeróbica), portanto, fez-se uma média global de remoção, para se ter uma noção da característica de remoção de carga orgânica no sistema de tratamento. Diferentemente da análise realizada na saída do sistema (lagoa de polimento) em que faz-se as amostragens simples para o efluente que será lançado ao corpo receptor.

Também deve ser levada em consideração a questão de oscilação do abate, a falta de rotina estabelecida no local e principalmente por serem realizadas a coleta das amostras sempre em períodos semelhantes. As amostragens, por serem retiradas das lagoas nas primeiras horas da tarde, não permitiram pegar picos de matéria orgânica, que podem ocorrer em outros períodos como no final da tarde ou até nas primeiras horas da manhã.

Através da análise para $\mathrm{DBO}_{5}$, apresentada na Tabela 5, foi possível inferir que apesar de o sistema de tratamento de lagoas do abatedouro avícola apresentar taxa de remoção global de matéria orgânica superior a $90 \%$ quando comparados os valores encontrados para a entrada e a saída, ainda assim estes valores não atingiram 
o determinado na licença de operação da empresa, onde o valor máximo permissível estabelecido pelo Instituto Ambiental do Paraná (IAP) foi de $50 \mathrm{mg} \cdot \mathrm{L}^{-1}$.

Tabela 4. Análise da $\mathrm{DBO}_{5}$ no sistema de lagoas de tratamento

\begin{tabular}{c|cc}
\hline mês & Lagoa anaeróbica - entrada DBO (mg.L-1) & $\begin{array}{c}\text { Lagoa de polimento - saída DBO } \\
\left(\mathrm{mg} . \mathrm{L}^{-1}\right)\end{array}$ \\
\hline 1 & 1332 & 128 \\
2 & 993 & 84 \\
3 & 1477 & 70 \\
4 & 1219 & 68 \\
5 & 1801 & 58 \\
6 & 1326 & 86 \\
\hline
\end{tabular}

Segundo o Standard Methods for the Examination of Water and Wastewater (APHA, 2012), a $\mathrm{DBO}_{5}$ mede a quantidade de oxigênio necessária para estabilizar biologicamente a matéria orgânica presente em uma amostra, após um determinado tempo, no caso 05 dias, e a uma temperatura padrão, de $20{ }^{\circ} \mathrm{C}$, e os resultados altos encontrados para $\mathrm{DBO}_{5}$ podem ser justificados, uma vez que o efluente de abatedouro avícola apresenta grande quantidade de matéria orgânica e desta forma as bactérias necessitarão de uma grande quantidade de oxigênio para estabilizar a matéria orgânica (CAIXETA et al., 2002; FATTA et al., 2003).

Para este caso específico, onde este efluente apresenta uma elevada quantidade de matéria orgânica biodegradável (Tabela 4), e que o mesmo é despejado no corpo hídrico sem apresentar as condições mínimas exigidas pelos órgãos fiscalizadores (IAP), pode acarretar ao corpo hídrico receptor em elevado consumo de oxigênio, com possíveis consequências: mortandade de peixes e condições sépticas (VON SPERLING, 2005; CAIXETA et al., 2002; FATTA et al., 2003; KHALID et al., 2011).

\subsubsection{Determinação da Demanda Química de Oxigênio - DQO}

Na Tabela 5 encontram-se os valores de DQO obtidos para as amostras 
coletadas na entrada e na saída do sistema de lagoas de tratamento. Assim como para os valores de $\mathrm{DBO}_{5}$, a DQO apresentou taxa de remoção global superior a 90\%, o que indica uma excelente remoção quando comparados os valores obtidos para a entrada e saída das lagoas, mas os valores de saída não enquadram o abatedouro avícola dentro das normas legais de lançamento de efluente, uma vez que os resultados obtidos nas análises da saída do sistema de tratamento foram superiores a $125 \mathrm{mg} / \mathrm{L}$, preconizado pelo IAP.

Tabela 5. Análise da DQO no sistema de lagoas de tratamento

\begin{tabular}{c|cc}
\hline mês & Lagoa anaeróbica - entrada DQO (mg. $\left.\mathrm{L}^{-1}\right)$ & $\begin{array}{c}\text { Lagoa de polimento - saída DQO } \\
\left(\mathrm{mg} . \mathrm{L}^{-1}\right)\end{array}$ \\
\hline 1 & 3174 & 306 \\
2 & 2816 & 251 \\
3 & 4230 & 205 \\
4 & 3080 & 257 \\
5 & 3889 & 150 \\
6 & 2662 & 255 \\
\hline
\end{tabular}

Através da Tabela 5 observa-se que o comportamento dos valores obtidos para DQO foram similares a $\mathrm{DBO}_{5}$ (Tabela 4), para os mesmos dias de análise e para ambas as análises, $\mathrm{DBO}_{5}$ e DQO, levou-se em consideração a questão da oscilação do abate ou por problemas ocasionados na planta; a falta de rotina estabelecida no local; assim como o período de chuvas ocasionado durante os períodos das coletas das amostras.

A DQO, assim como a $\mathrm{DBO}_{5}$, permite avaliar a não formação de picos de matéria orgânica na entrada do sistema de lagoas (lagoa anaeróbica), fatores estes resultantes da característica das amostragens simples realizadas e dos períodos regulares em que foram coletadas as amostras. Outro ponto importante a se mencionar é o fato de que as análises de $\mathrm{DBO}_{5}$ e DQO partiram das mesmas amostras de efluente. Verificou-se que a concentração de matéria orgânica foi reduzida significativamente, o que denota os valores médios de remoção superiores a 80\% quando comparados os valores de DQO para a entrada e saída do sistema de lagoa 
de tratamento, mesmo assim não sendo o suficiente para garantir uma remoção adequada para ser descartada no corpo hídrico.

\subsubsection{Determinação de Nitrogênio e Fósforo}

Os abatedouros avícolas, assim como outras atividades industriais, apresentam nitrogênio e fósforo em grandes concentrações e constitui-se em um dos principais nutrientes para os processos biológicos, ou seja, é um dos chamados macronutrientes, por estar presente também em grandes quantidades pelas células (ESTEVES, 2011). Assim, estes parâmetros de nitrogênio e fósforo, mostrados na Tabela 6, são imprescindíveis na caracterização do efluente, uma vez que se destinados ao corpo hídrico receptor em valores superiores aos máximos permissíveis, pode ocorrer a eutrofização do ambiente aquático.

As variações encontradas nos valores de nitrogênio para a lagoa anaeróbica - LA devem estar associadas às variações nas quantidades de aves abatidas, uma vez que a quantidade de nitrogênio está diretamente ligada à composição química dessas aves na estrutura dos aminoácidos. Comparando-se os resultados obtidos para a lagoa de polimento - LP com a Resolução CONAMA n ${ }^{\circ}$ 430, de 2011, os valores encontrados para a saída do sistema encontram-se superiores ao valor máximo permissível de $20 \mathrm{mg} / \mathrm{L}$, mesmo quantificando através das análises uma taxa de remoção média superior a $80 \%$.

Tabela 6. Concentração de nitrogênio e fósforo encontrada nas lagoas anaeróbica - LA e de polimento - LP

\begin{tabular}{c|cccc}
\hline \multicolumn{2}{c}{} & \multicolumn{2}{c}{ Nitrogênio $(\mathrm{mg} / \mathrm{L})$} & \multicolumn{2}{c}{ Fósforo $(\mathrm{mg} / \mathrm{L})$} \\
\cline { 2 - 5 } & LA & LP & LA & LP \\
\hline $1^{\circ}$ mês & 135 & 32 & 22 & 5 \\
$2^{\circ}$ mês & 317 & 22 & 17 & 3 \\
$3^{\circ}$ mês & 368 & 40 & 17 & 3 \\
$4^{\circ}$ mês & 372 & 64 & 15 & 17 \\
$5^{\circ}$ mês & 205 & 33 & 24 & 15 \\
$6^{\circ}$ mês & 246 & 27 & 8 & 8 \\
\hline
\end{tabular}

LA = lagoa anaeróbica (entrada) e LP = lagoa de polimento (saída). 
Observa-se que os valores encontrados demonstram variação da concentração de fósforo (Tabela 6), fato que se deve em função deste elemento sedimentar ao fundo da lagoa. Para as análises do $4^{\circ}$ e $6^{\circ}$ mês, praticamente não houve alteração dos valores, quando comparadas entrada e saída do sistema, o que pode ser justificado em função da produção de gases gerados por bactérias que elevam o sedimento das lagoas podendo contaminar, assim, as amostras a serem analisadas.

Os valores encontrados para análise de fósforo na lagoa de polimento (Tabela 6) estão fora dos parâmetros exigidos pela Resolução CONAMA no 357 , de 2005 , a qual estabelece o valor máximo permissível de $0,5 \mathrm{mg} / \mathrm{L}$ e em todas as análises os resultados ficaram muito acima do permitido.

A presença elevada de nutrientes como fósforo e nitrogênio, $\mathrm{DBO}_{5}$ e DQO no efluente que será lançado no corpo hídrico receptor, pode levar a um crescimento excessivo de algas, que por sua vez pode ser associada à produção de toxinas por estas algas, e desta forma provocar um desequilíbrio ecológico e poluição da água subterrânea (VON SPERLING, 2005; ESTEVES, 2011).

A relação de DBO/Nitrogênio/Fósforo pode ser associada como indicadora da viabilidade do tratamento biológico, sendo considerada a relação 100:5:1 como necessária para manter um balanço adequado de matéria orgânica e nutrientes para o tratamento biológico (BEAL; MONTEGGIA; GIUSTINA, 2006). Porém verificou-se que esta relação não foi alcançada no abatedouro avícola em questão, mostrando mais uma vez que o sistema de lagoas para tratamento do efluente não está sendo eficiente e como consequência o corpo hídrico receptor está recebendo uma carga de poluição que ao longo dos anos pode levar a um desequilíbrio ecológico, através da diminuição de oxigênio dissolvido na água, aparecimento de quantidades elevadas de algas e mortandade de peixes (ALMEIDA et al., 2010; JORDÃO; PESSÔA, 2005).

Um efluente, além de satisfazer os padrões de lançamento, deve proporcionar condições ao corpo hídrico receptor, de tal forma que a qualidade do mesmo se enquadre dentro dos padrões para corpos receptores. Porém, esse fato não foi observado no abatedouro avícola em questão, e é motivo de preocupação, uma vez que está poluindo o corpo hídrico receptor e causando danos ao meio ambiente e à 
população, necessitando assim, de redimensionamento e melhorias no seu sistema de tratamento de efluentes (VON SPERLING, 2005; ESTEVES, 2011).

\section{CONSIDERAÇÕES FINAIS}

O sistema de lagoas de tratamento de efluentes do abatedouro avícola estudado mostrou-se ineficiente em seu processo, tanto na parte microbiológica, onde o tratamento de efluente do abatedouro avícola não apresentou remoção adequada para a carga microbiana, quanto nas análises físico-químicas de $\mathrm{DBO}_{5}, \mathrm{DQO}$, nitrogênio total e fósforo, uma vez que para os parâmetros apesar de fornecerem taxa de remoção global superior a 90\% e 80\%, respectivamente, apresentou valores superiores aos preconizados na licença de operação não atingindo os valores máximos permissíveis para lançamento do efluente no corpo hídrico receptor.

As análises apresentadas mostram a necessidade imediata de redimensionamento e de melhorias no sistema de tratamento do efluente do abatedouro avícola em estudo, bem como uma fiscalização mais rigorosa pelos órgãos competentes.

\section{REFERÊNCIAS}

ALMEIDA, R. A.; PITALUGA, D. P. S.; REIS, R. P. A. Tratamento de esgoto doméstico por zona de raízes precedida de tanque séptico. REVISTA BIOCIÊNCIAS, v. 16, n. 1, p. 73-81, 2010.

ALVAREZ, R.; LIDÉN, G. Semi-continuos co-digestion of solid slaughterhouse waste, manure, and fruit and vegetable waste. Renewable Energy, v. 33, p. 726-734, 2008.

APHA, AWWA, WEF. Standard Methods for examination of water and wastewater. 22nd ed. Washington: American Public Health Association, 2012. 1360p.

BARROS, L. S. S.; SILVA, R. M.; SILVA, I. M. M.; BALIZA, M.; FREITAS, F. A Avicultura brasileira e sua afinidade com a celulite aviária. Arquivos de Pesquisa Animal, v. 1, n. 2, p. 78-97, 2012. 
BARROS, L. S. S.; AMARAL, L. A.; LORENZON, C. S.; JUNIOR, J. L.; MACHADO NETO, J. G. Potential microbiological contamination of effluents in poultry and swine abattoirs. Epidemiol. Infect., v. 135, p. 505-518, 2007.

BEAL, L. L.; MONTEGGIA, L. O.; GIUSTINA, S. V. D. Otimização de uma Estação de Tratamento de Efluentes de uma Indústria de Embalagens de Papel. Engenharia Sanitária e Ambiental, v. 11, n. 3, jul./set., p. 283-289, 2006.

BRASIL. Resolução CONAMA no 357, de 18 de março de 2005. Dispõe sobre a classificação dos corpos de água e diretrizes ambientais para o seu enquadramento, bem como estabelece as condições e padrões de lançamento de efluentes, e dá outras providências. Brasília: Sema, 2005.

BRASIL. Resolução CONAMA no 430, de 13 de maio de 2011. Dispõe sobre as condições e padrões de lançamento de efluentes, complementa e altera a Resolução $\mathrm{n}^{0}$ 357, de 17 de março de 2005, do Conselho Nacional do Meio Ambiente - CONAMA. Brasília: Sema, 2011.

CAIXETA, C. E. T.; CAMMAROTA, M. C.; XAVIER, A. M. F. Slaughterhouse wastewater treatment: evaluation of a new three-phase separation system in a UASB recator. Bioresource Technology, v. 81, n. 1, p. 61-69, 2002.

CHEN, Y.; CHENG, J. J.; CREAMER, K. S. Inhibition of anerobic digestion process: A review. Bioresource Technology, v. 99, p. 4044-4064, 2008.

ESTEVES, F. A. Fundamentos de Limnologia. 3. ed. Rio de Janeiro: Interciência, 2011. 790p.

FATTA, D.; MARNERI, M.; PAPADOPOULOS, A.; MOUSTAKAS, K.; HARALAMBOUS, K. J.; LOIZIDOU, M. Development of guidelines on best practices for the slaughter of animals in Cyprus. Waste Management, v. 23, n. 2, p. 157-165, 2003.

JORDÃO, E. P.; PESSÔA, C. A. Tratamento de Esgotos Domésticos. 3. ed. Rio de Janeiro: ABES, 2005. 932p.

KHALID, A.; ARSHAD, M.; ANJUM, M.; MAHMOOD, T.; DAWSON, L. The anaerobic 
digestion of solid organic waste. Waste Management, v. 31, p. 1737-1744, 2011.

MENDHAM, J.; DENNEY, R. C.; BARNES, J. D.; THOMAS, M. J. K. Vogel: Análise Química Quantitativa. 6. ed. Rio de Janeiro: LTC, 2002.

MENEGAZ, R. C.; BACCARIN, L. I. P.; HEMKEMEIER, M.; BACCARIN, S. D.; DEROSSI, A.; DECESARO A.; FABRIS, E. Remoção Físico-química de Fósforo por Flocosedimentação Aplicada ao Pós-tratamento de Efluente de Abatedouro Avícola. Recen, v. 13, n. 2, p. 227-255, 2011.

MOLINO, A.; NANNA, F.; DING, Y.; BIKSON, B.; BRACCIO, G. Biomethane Production by Anaerobic Digestion of Organic Waste. Fuel, v. 103, p. 1003-1009, 2013.

OLIVEIRA, A. B. M. et al. Biodigestão anaeróbia de efluente de abatedouro avícola. Rev. Ceres, Viçosa, Viçosa, v. 58, n. 6, p. 690-700, 2011.

SALMINEN, E.; RINTALA, J. Anaerobic digestion of organic solid poultry slaughterhouse waste: a review. Bioresource Technology, v. 83, p. 13-26, 2002.

SILVA, N.; CANTÚSIO NETO, R.; JUNQUEIRA, V. C. A.; SILVEIRA, N. F. A. Manual de métodos de análise microbiológica da água. São Paulo: Livraria Varela, 16p., 2005.

VON SPERLING, M. Introdução à Qualidade das Águas e ao Tratamento de Esgotos (Princípios do tratamento biológico de águas residuárias: Lagoas de estabilização). Belo Horizonte: DESAUFMG, 2005. v. 1.

ZENATTI, D. C.; GOMES, S. D.; FAZOLO, A.; COSTANZI, R. N.; HASAN, S. D. M.; GENTELINI, A. L. Nitrificação de Efluente de Abatedouro de Tilápia em Função da Aeração e Tempo de Reação, Revista Brasileira de Engenharia Agrícola e Ambiental, v. 13, n. 6, p. 750-754, 2009.

Recebido: 08 de setembro de 2014 Aceito: 23 de agosto de 2015 